\title{
Radical change or warm sentiments? A commentary on Gronholm et al. (2017) Interventions to reduce discrimination and stigma: the state of the art
}

\author{
Alison Faulkner ${ }^{1}$ \\ Received: 17 March 2017 / Accepted: 1 May 2017/Published online: 12 May 2017 \\ (C) Springer-Verlag Berlin Heidelberg 2017
}

The paper by Gronholm et al. left me feeling rather hopeless about initiatives to reduce stigma and discrimination; it reads as if both research and anti-stigma campaigns are tinkering around the edges of stigma and discrimination but ultimately making little real impact. The paper gives an overview of the 'state of the art' regarding anti-stigma interventions and research to evaluate their effectiveness. They conclude that intervening to reduce stigma and discrimination 'requires a long term, sustained commitment' and there is a need to improve both the evaluation methods and the interventions themselves. They recommend bigger and better randomised study designs and evidence-based teaching and assessment methods to improve the interventions. And yet, there is poor evidence to date for anything but small and short-term effects and only then within certain specific audiences.

The words stigma and discrimination are repeated so frequently that I wonder if we have almost forgotten what it really means to experience them. When reading this article, I felt this acutely; the somewhat abstract discussion of interventions and research to address or reduce stigma left me cold. I found myself drawn to reading personal accounts and survivor research that reflects that reality.

'My family really did not understand mental illness.

When I was a kid we were told that to commit suicide was the most selfish thing you could ever do; if you are committing suicide you are punishing your family

This comment refers to the article available at doi:10.1007/s00127017-1341-9.

Alison Faulkner

alison.faulkner2@btinternet.com

7 Elsiedene Road, London N21 2RN, UK forever. and um yeah, being depressed was a sign of weakness, a real sign of weakness.' (Quoted in [1])

'Keeping in touch with friends-reaction is usually one of shock, horror, followed by avoidance; most people have no idea how hard it is. This leaves me feeling very isolated and with low self confidence.'(Quoted in [7])

Perhaps, we need to remember that we are talking about social exclusion and marginalisation. Stigma and discrimination affect people's lives; in fact, as is mentioned in the paper by Gronholm et al., it can be 'worse than the experience of the mental illness itself' (page ref). I first heard this sentiment expressed when carrying out survivor research in the late 1990s. We were asking people about the different factors that they found helpful in living with mental distress [3]. What we found was that many people were seeking out ways of ameliorating stigma and discrimination: seeking out people and places where they felt safe, spending time in self-help and peer support groups, day centres, and drop-ins, where they found a sense of belonging and acceptance.

One of the reasons for the failure of anti-stigma campaigns to have much impact on stigma/discrimination is referred to in passing in this paper: the failure or inability to address structural discrimination. The Government may well be prepared to fund anti-stigma programmes that address interpersonal stigma with one hand, but with the other hand, they are feeding stigma and discrimination through welfare reforms and service cuts that render people more disadvantaged and stigmatised as 'benefits scroungers', potentially to the point of suicide. ${ }^{1}$ A recent report by

\footnotetext{
${ }^{1}$ See: http://www.disabilitynewsservice.com/billions-of-pounds-ofpip-cuts-will-put-lives-at-risk/.
} 
the Samaritans [5] concluded that people who are socioeconomically disadvantaged or who live in areas of socioeconomic deprivation are at increased risk of suicide. Features of socio-economic disadvantage include low income, unmanageable debt, poor housing conditions, lack of educational qualifications, unemployment, and living in a socio-economically deprived area.

If one of the purposes of reducing stigma is to encourage people to seek help, then we need to be realistic about what help is available to people experiencing mental distressand when. What we know is that it is not easy to access help when you need it, particularly in these times of austerity. More worrying still is the finding that, for some people, it is health and social care staff who are amongst the worst offenders when it comes to stigma and discrimination. This is acknowledged in the paper by Gronham et al., but merits further examination. Why is it that when people do seek help they often experience such negative attitudes from mental health practitioners? The impact of this can be considerable because of the power that healthcare staff have to give or to withhold access to treatment and care. In addition to which, people may be reluctant to disclose a mental illness diagnosis when seeking physical health care.

'Stigma and discrimination has stopped me talking to my GP about physical problems, they say it's in my head.' (Quoted in [7])

Bonnington and Rose [1] found that negative attitudes from healthcare practitioners particularly emerged in relation to a diagnosis of borderline personality disorder; indeed, stereotypes relating to this diagnosis were thought to have originated from healthcare staff.

'When it came up on the [GP's computer] that I had BPD he spoke to me differently [compared] to what he did originally... he was asking me to describe how I was feeling, physically, and then he asked about medication, but he was fiddling around with his PC and when it came up it was like he put it all down to that [the BPD]—'well, that's why you feel like that'.'(Quoted in [1])

'Psychiatrists are the worst... they need to stop telling people it's their fault, it just makes a person [feel] worse.' (Quoted in [1])

This raises the issue of the impact of different diagnoses on the experience of stigma and discrimination. For many members of the public, it is relatively 'acceptable' to have a diagnosis of depression or anxiety, but diagnoses such as schizophrenia or personality disorder give rise to more difficult and problematic images (violence, unpredictability, and blame) that carry greater stigma.
In contrast, most public anti-stigma campaigns rely on a sanitised approach to images of mental illness to maximise the potential for the public to identify with and understand the people affected. These campaigns appeal to public sympathy with their normalised, acceptable images of mental illness, intended to invoke a combination of pity or sympathy and a sense of power to do good. This concept referred to by Grey [4] as 'benevolent othering', which she defines as a tendency to speak of others in ways that are ostensibly positive but which function to 'maintain the subordination of mental health service users'. As Mark Brown [2] points out, 'anyone can endorse nice sentiments', but meanwhile, many people with mental illness diagnoses are experiencing shorter, poorer lives, and facing further disadvantage in this time of austerity through cuts to both services and welfare benefits. The imbalance of power is sustained through campaigns that appeal to the benevolence of the public to be bestowed upon a disadvantaged and apparently powerless and pitiful minority.

Anti-stigma campaigns also tend to feature well-known celebrities, which is likely to have a mixed effect, because most of us will understand these people to be special or different- 'other' in another way. As someone said to me just this week 'It's ok for Stephen Fry to say he's bipolar, but that's not real life'. It may be Stephen Fry's real life, but it is hard for many people with a diagnosis of bipolar to identify with him. The impact might be to perpetuate the myth of bipolar as exciting and creative, the source of artistic talent.

These campaign images fail to address difficult or complex issues resulting from people's intersectional experiences of stigma/discrimination arising from racism and marginalisation on other grounds, because that would complicate the message. However, in the process, they may well be increasing the stigma/discrimination subsequently afforded to the less 'acceptable' groups such as people with a diagnosis of borderline personality disorder or schizophrenia, people from black and minority ethnic communities, homeless people, and people from LGBT+ communities (amongst others). By making some people and some conditions worthy of 'benevolent othering', the campaigns may be further alienating people who do not fit this worthy category [4].

Social contact approaches to reducing stigma can have a positive but short-term effect, and there is a problem with the phenomenon of 'discounting'. This means that people can change their attitudes towards the persons with whom they have contact but retain their attitudes towards the group they represent. We still retain our attitudes towards the 'other' based on deeply entrenched stereotypes of groups who are 'not us'. The other flaw is that, for social contact approaches to work well, the people involved need to share equal status and common goals and be in a 
reciprocal relationship. This is hard to achieve in the presence of stigma/discrimination as is touched on in this paper.

Another important issue is to consider the nature of the information or knowledge being promoted through educational and public media campaigns. Sayce [6] notes that illness-based explanations tend to have a negative effect on public attitudes; they tend to be associated with more prejudice and fear. An important point is that measures of positive attitudes in evaluating the impact of these interventions include endorsement of the illness/disease model; this completely undermines the interpretation of these results, since it could indicate an increase in negative attitudes rather than in positive attitudes. Sayce concludes that the dominant biological explanation for mental health may support help-seeking but at the same time increases stigma and discrimination.

The situation does feel fairly hopeless. Rather than bigger and better trials, I would suggest that we need political and structural changes to support the equality of people diagnosed with mental illness, the real contribution of service user/survivor experiential knowledge into codesigning anti-discrimination initiatives, and a stronger focus on those who are meant to provide the care and support that people are encouraged to seek. As stated by Mark Brown [2], until the dominant majority is prepared to alter the structures, laws and practices that benefit them in favour of those they discriminate against, 'all we have is warm sentiments'.

\section{Compliance with ethical standards}

Conflict of interest The author notes no conflict of interest in connection with this article.

\section{References}

1. Bonnington O, Rose D (2014) Exploring stigmatisation among people diagnosed with either bipolar disorder or borderline personality disorder: a critical realist analysis. Soc Sci Med 123:7-17

2. Brown M (2017) Kindness is nice, but here's what people with mental health issues really need from you. The Guardian: comment is free 2 February 2017. http://www.theguardian.com/commentis free/2017/feb/02/time-to-talk-day-mental-health-sympathy-wel come-solidarity-go-further

3. Faulkner A, Layzell S (2000) Strategies for living: a report of userled research into people's strategies for living with mental distress. Mental Health Foundation, London

4. Grey F (2016) Benevolent othering: speaking positively about mental health service users. Philos Psychiatry Psychol 23(3/ 4):241-251 (September/December)

5. Samaritans (2017) Dying from inequality: socioeconomic disadvantage and suicidal behaviour. Samaritans, Ewell

6. Sayce L (2014) Why talk of illness entrenches discrimination. Mental Health Soc Incl 18(2):68-76

7. Time to Change (2008) Stigma Shout: service user and carer experiences of stigma and discrimination. Rethink Mental Illness, London 